\title{
EFEITO DA ORIENTAÇÃO DE LAMINAÇÃO NA RESISTÊNCIA AO DESGASTE ABRASIVO DE UM AÇO ASTM A242*
}

\author{
Maria Vianna Rigatto ${ }^{1}$ \\ Daniela Fátima Giarollo² \\ Cintia Cristiane Petry Mazzaferro 3 \\ José Antônio Esmerio Mazzaferro ${ }^{4}$
}

\section{Resumo}

Nesse trabalho, foram realizados ensaios de abrasão do tipo roda de borracha em um aço ASTM A242, com o intuito de verificar se a orientação do desgaste em relação à da laminação influencia no comportamento em desgaste do material. Estes ensaios foram executados seguindo a norma ASTM G65-16. Todas as amostras foram fresadas e lixadas para a realização dos ensaios, além de limpas com acetona para medição da massa tanto antes quanto depois do ensaio de desgaste. Utilizando a massa perdida após o ensaio e considerando um possível desgaste da roda de borracha, foi calculado o volume perdido nos ensaios. Além disso, foi medida a microdureza do aço, nos sentidos transversal e longitudinal à laminação, bem como analisadas as microestruturas nos respectivos sentidos antes e depois dos ensaios de desgaste. Os resultados mostraram que a orientação do desgaste em relação à orientação de laminação possui influência na taxa de desgaste e que no sentido transversal à laminação essa taxa foi 9,6\% menor que no sentido longitudinal.

Palavras-chave: Ensaio de abrasão; Microestrutura; Sentido de laminação; Aço.

\section{EFFECT OF ROLLING ORIENTATION ON THE ABRASIVE WEAR RESISTANCE OF AN ASTM A242 STEEL}

\section{Abstract}

In this work, abrasion tests of the rubber wheel type were carried out on an ASTM A242 steel, in order to verify if the orientation of the wear in relation to the rolling direction influences the wear behavior of the material. These tests were performed following the ASTM G65-16 standard. All samples were milled and grinded for the tests, and cleaned with acetone for mass measurement both before and after the wear tests. Using the mass loss after the test and considering a possible wear of the rubber wheel, the volume loss in the tests was calculated. In addition, the microhardness of the steel in the transverse and longitudinal directions was measured, as well as the microstructures analyzed in the respective directions before and after the wear tests. The results showed that the wear orientation in relation to the rolling orientation influences the wear rate and that in the transverse direction this rate was $9.6 \%$ lower than in the longitudinal direction.

Keywords: Abrasion test; Microstructure; Rolling orientation; Steel.

1 Estudante do curso de graduação em Engenharia Metalúrgica da Universidade Federal do Rio Grande do Sul, Porto Alegre, Rio Grande do Sul e Brasil.

2 Engenheira Mecânica, Mestranda no Laboratório de Soldagem \& Técnicas Conexas da Universidade Federal do Rio Grande do Sul, Porto Alegre, Rio Grande do Sul, Brasil.

3 Profa. Dra. Pesquisadora no Laboratório de Soldagem \& Técnicas Conexas da Universidade Federal do Rio Grande do Sul, Porto Alegre, Rio Grande do Sul, Brasil.

4 Prof. Dr. Pesquisador e Coordenador do Laboratório de Soldagem \& Técnicas Conexas da Universidade Federal do Rio Grande do Sul, Porto Alegre, Rio Grande do Sul, Brasil. 


\section{INTRODUÇÃO}

$\mathrm{Na}$ indústria e na natureza existem muitos tipos de desgastes. Baptista e Nascimento[1] classificam os desgastes por erosão, cavitação, adesão, abrasão, impacto ou desgaste corrosivo. De acordo com eles, o desgaste por erosão é devido ao choque contra a superfície, de partículas sólidas ou gotas líquidas. O desgaste por cavitação está relacionado com a formação de bolhas gasosas em correntes de fluidos, na interface líquido-metal, resultado da variação rápida de pressão ao longo do percurso. O desgaste por abrasão é ocasionado por partículas duras sob tensão, que se deslocam sobre a superfície. Já o desgaste por adesão é descrito como um resultante da fabricação metal-metal, quando duas superfícies ásperas deslizam entre si. O desgaste corrosivo envolve a ocorrência de reações químicas superficiais no material, além de ações mecânicas de desgaste. E por último eles descrevem o desgaste por impacto, que é ocasionado por cargas aplicadas verticalmente ou choques sobre a superfície.

Dettogni[2] cita que o desgaste, além de envolver a deformação e o corte superficial por partículas abrasivas, ou o atrito entre superfícies metálicas, deveras vezes acontece devido à vários mecanismos concomitantes de desgaste da superfície, os quais podem também estar relacionados a outros fenômenos de degradação, como corrosão, fadiga ou impacto.

A norma ASTM G40[3] define desgaste abrasivo como o desgaste devido a partículas duras ou protuberâncias duras forçadas contra e se movendo em uma superfície sólida. Já Eyre[4] descreve esse tipo de desgaste como a degradação da superfície do equipamento ou do componente, incluindo remoção progressiva do material, como resultados de processos tribológicos. Ele constatou que de todos os problemas industriais envolvendo desgaste, 0 desgaste abrasivo compreende aproximadamente $50 \%$ deles. Portanto, ele é de grande importância e por isso foi escolhido para ser usado nesse estudo.

A literatura indica dois modelos básicos de desgaste abrasivo, o de dois corpos e o de três corpos. O ensaio abrasivo a dois corpos se caracteriza, conforme Kovaříková et al[5], por grãos presos de maneira rígida passando sobre uma superfície, como uma ferramenta de corte. Já no ensaio abrasivo a três corpos, os grãos são livres para rolar e deslizar sobre a superfície, já que não são mantidos presos rigidamente.

Um ensaio abrasivo a três corpos muito utilizado na literatura é o tipo roda de borracha. Ele consiste em um disco de aço revestido com uma borracha que gira em contato com a superfície do corpo de prova, com algum tipo de abrasivo entre eles, e possui alta confiabilidade de resultados, segundo Villabón e Sinatora [6].

O desgaste é um fenômeno complexo. Baptista e Nascimento[1], citam haver uma relação entre a resistência ao desgaste e a dureza dos materiais. Essa relação nos materiais ferrosos não é simples. Por exemplo, a medida que o teor de carbono aumenta a resistência ao desgaste também aumenta. Em aços com porcentagem igual de carbono, fica claro que um aço ligado tem resistência ao desgaste maior do que a de um aço sem liga, mas este aumento é pequeno quando comparado com outro em que se aumentou a porcentagem de carbono.

No presente trabalho, foram realizados ensaios de desgaste abrasivo do tipo roda de borracha em um aço ASTM A242, que possui microestrutura ferríticoperlítica, com o objetivo de avaliar se a orientação de direção do desgaste, em relação ao sentido de laminação do material, transversal ou longitudinal, influencia no seu comportamento em desgaste. 


\section{MATERIAIS E MÉTODOS}

O material utilizado é um aço ASTM A242 laminado à quente com espessura de 4,75 mm. Os corpos de prova foram cortados nas dimensões $75 \times 25 \times 4,75 \mathrm{~mm}$, observando a orientação de laminação. Foi importante ter esse cuidado, pois o objetivo desse trabalho é analisar a influência da orientação da laminação no desgaste.

$\mathrm{Na}$ tabela 1 pode-se verificar a diferença entre os valores de dureza nas duas orientações em relação à laminação. Para a medição da dureza Vickers foi utilizado um microdurômetro (Insize) com uma carga de 300 gramas aplicada durante 10 segundos. Os resultados mostram que no sentido transversal, a dureza do material é menor do que no sentido longitudinal.

Tabela 1: Médias e desvios da dureza do material utilizado no estudo.

\begin{tabular}{ccc}
\hline & Durezas & \\
\hline Sentido em relação à & Longitudinal & Transversal \\
laminação & & \\
Média & $157,6 \mathrm{HV}$ & $144,9 \mathrm{HV}$ \\
Desvio & $8,6 \mathrm{HV}$ & $4,4 \mathrm{HV}$ \\
\hline
\end{tabular}

Para os ensaios de desgaste serem realizados foram necessários uma série de procedimentos. Após cortar os corpos de prova, foi preciso fresar todos eles para que o possível empenamento dos corpos de prova não afetasse os ensaios. Em seguida, suas superfícies que seriam ensaiadas foram lixadas começando pela lixa de 80 mesh até a lixa de 600 mesh, e limpas com acetona para a posterior medição da massa em uma balança com precisão de quatro casa decimais. Ao determinar a massa inicial, o corpo de prova estava pronto para ser posicionado no portaamostras. Antes do ensaio abrasivo começar, o fluxo de areia (utilizada como o "terceiro corpo") foi medido, assim como o diâmetro da roda de borracha. Depois do ensaio, a amostra foi novamente limpa com acetona para a medição da massa final, assim como o diâmetro da roda de borracha foi igualmente medido. Conhecendo-se o valor da massa final, foi calculada massa perdida em cada ensaio de desgaste, considerando o possível desgaste da roda de borracha. Foram efetuadas três repetições para cada condição estudada.

Como a figura 1 ilustra, o corpo de prova é fixado a um porta-amostras com um contrapeso que ao ser liberado provoca uma força normal à roda de borracha, ocasionando o atrito entre o sistema corpo de prova/borracha/areia. O bocal é por onde cai a areia devido à força da gravidade.
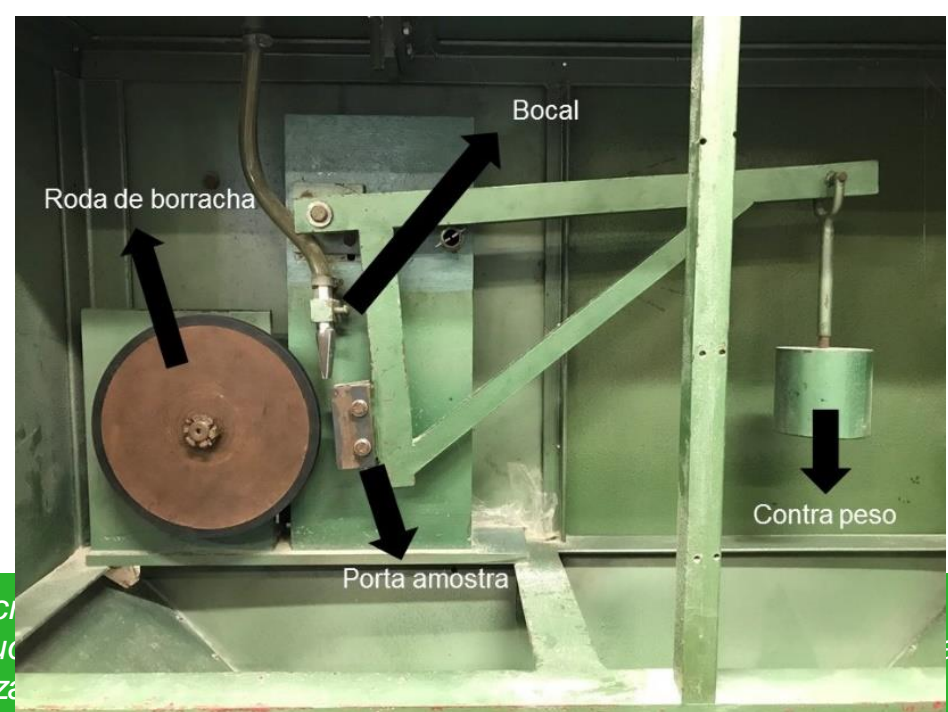
Figura 1: Máquina de ensaios abrasivo à três corpos do tipo roda de borracha.

$\mathrm{Na}$ tabela 2 estão apresentados os parâmetros utilizados nos ensaios realizados nos corpos de prova.

Tabela 2: Parâmetros utilizados nos ensaios abrasivos do tipo roda de borracha.

\begin{tabular}{cc}
\hline & Parâmetros de ensaio \\
\hline Procedimento & B da norma ASTM G65 2016 \\
Força & $130 \mathrm{~N}$ \\
Tempo médio & 10 minutos \\
Revoluções & 2000 \\
Fluxo abrasivo médio & $296 \mathrm{~g} / \mathrm{min}$ \\
Rotação média & $200 \mathrm{RPM}$ \\
Granulometria da areia & $150-212 \mu \mathrm{m}$ \\
Borracha & Neoprene com dureza 74 Shore A \\
\hline
\end{tabular}

Segundo a Equação 1, descrita na norma ASTM G65-16 [7], foi calculado o volume perdido utilizando a massa perdida medida anteriormente.

$$
\Delta V=\frac{\Delta m}{\rho}
$$

Sendo $\Delta \mathrm{V}$ a variação de volume, ou seja, o volume desgastado em milímetros cúbicos; $\Delta \mathrm{m}$ a variação de massa em gramas; $\rho$ a massa específica do material em gramas por milímetros cúbicos, que para esse aço foi utilizado o valor de $7,85 \mathrm{~g} / \mathrm{cm}^{3}$. Entretanto, é necessário considerar o possível desgaste na roda de borracha para o cálculo do volume perdido se tornar mais exato. Para isso, foi utilizada a Equação 2, também descrita na norma ASTM G65-16 [7].

$$
A V L=\Delta V x \frac{\text { Diâmetro da roda antes do ensaio }}{\text { Diâmetro da roda após o ensaio }}
$$

Sendo AVL a perda de volume ajustado em milímetros cúbicos; o $\Delta \mathrm{V}$ o volume perdido calculado anteriormente em milímetros cúbicos, e os diâmetros da roda de borracha já descritos na equação, em milímetros.

As superfícies desgastadas foram avaliadas em um perfilômetro Brucker para a visualização e posterior comparação das superfícies de desgaste. Após, os corpos de prova foram cortados no meio da trilha desgastada, transversal a ela, e embutidos com um ângulo $20^{\circ}$ de maneira que houvesse um aumento na imagem da microestrutura logo abaixo das indentações deixadas pela areia na superfície das amostras ensaiadas, com objetivo de, se possível, identificar a influência da microestrutura no processo de desgaste das amostras ensaiadas, utilizando um microscópio ótico (Zeiss Axio Lab.A1).

\section{RESULTADOS}

A composição química do aço ASTM A242 pode ser vista na tabela 3 e a sua microestrutura, composta por ferrita e perlita, pode ser observada na figura 2, nos 
sentidos longitudinal e transversal à laminação. Percebe-se que os grãos de ferrita encontram-se equiaxiais, e que não pode ser observada uma textura (de laminação) proeminente no material. No entanto, verificou-se que a resposta ao ataque químico era diferente para ambos sentidos, sendo a microestrutura no sentido transversal mais suscetível ao ataque do que a no sentido longitudinal.

Tabela 3: Composição química do aço ASTM A242 utilizado no estudo (\% em peso).

\begin{tabular}{cccccccccc}
\hline $\mathrm{C}$ & $\mathrm{Mn}$ & $\mathrm{Si}$ & $\mathrm{Cr}$ & $\mathrm{Co}$ & $\mathrm{Al}$ & $\mathrm{Cu}$ & $\mathrm{Ni}$ & $\mathrm{Nb}$ & $\mathrm{Fe}$ \\
\hline 0,082 & 0,617 & 0,416 & 0,033 & 0,0063 & 0,04 & 0,24 & 0,119 & 0,0085 & 98,42 \\
\hline
\end{tabular}
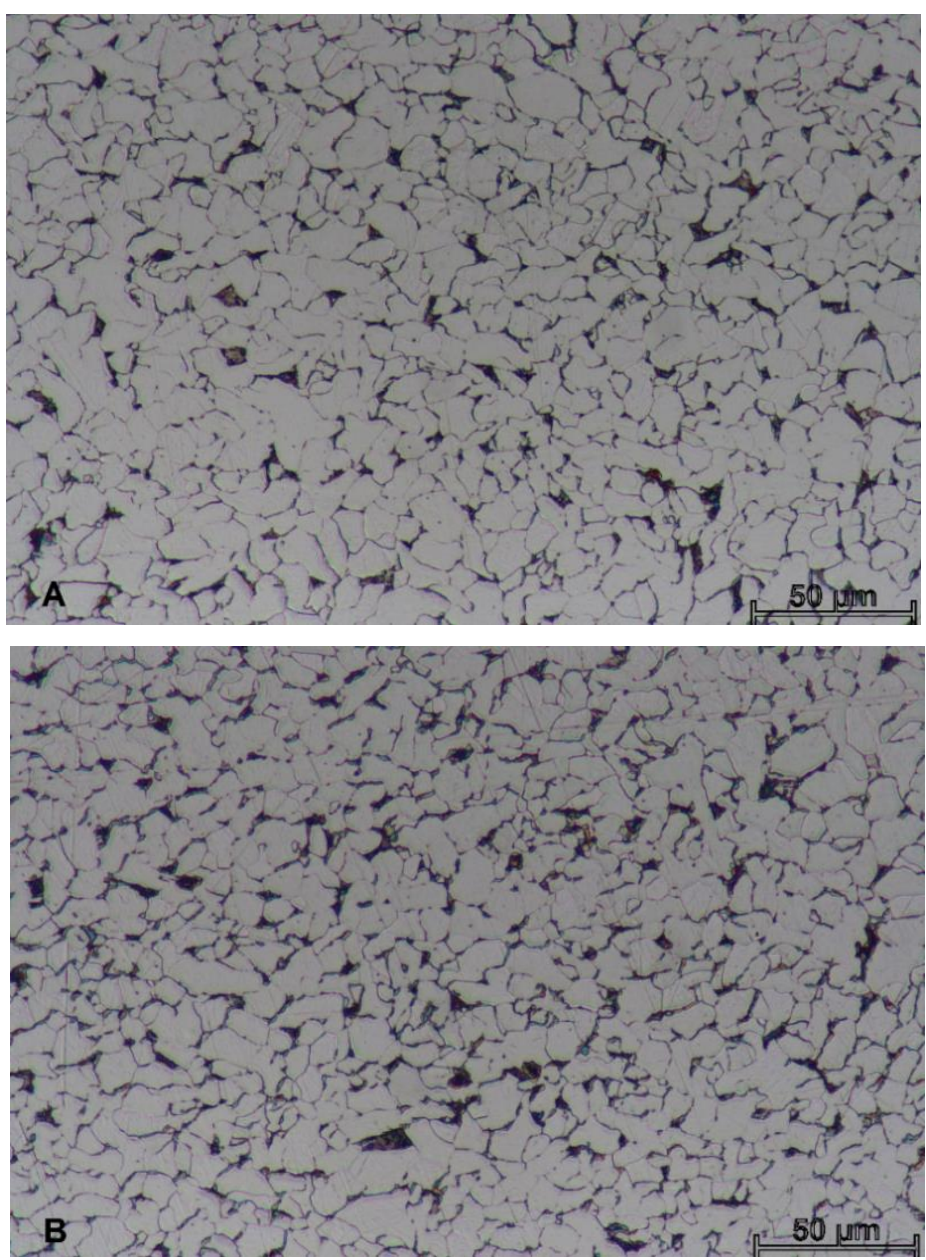

Figura 2: Microestrutura do material nas direções longitudinal $(A)$ e transversal $(B)$ ao sentido de laminação da chapa. Fase branca = ferrita; fase escura = perlita. Ataque químico com Nital $10 \%$.

A Figura 3 apresenta os valores médios do desgaste, em volume, e seu respectivo desvio em relação aos três ensaios feitos para cada direção de laminação. Os resultados mostram que o desgaste no sentido transversal à laminação é menor $\left(6,7 \mathrm{~mm}^{3} \pm 3,3\right)$ do que o desgaste no sentido longitudinal à laminação $\left(7,4 \mathrm{~mm}^{3} \pm 2,5\right)$.

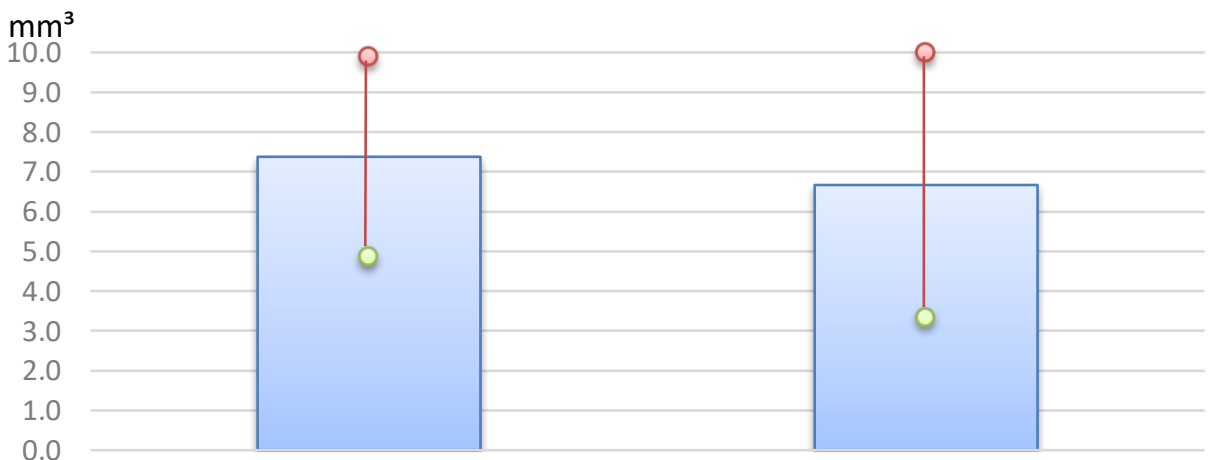


Figura 3: llustração dos valores médios e desvios do volume desgastado, para ambas condições estudadas.

A Figura 4 mostra as imagens com as microestruturas dos corpos de prova após os ensaios de desgaste. Pode-se observar no topo das imagens a superfície de desgaste, resultante do atrito à três corpos (roda de borracha, areia e metal). Nas duas condições estudadas, pôde-se perceber a deformação plástica da microestrutura logo abaixo da superfície desgastada, porém em ambos casos essas regiões deformadas se limitam (em profundidade) à poucos grãos.

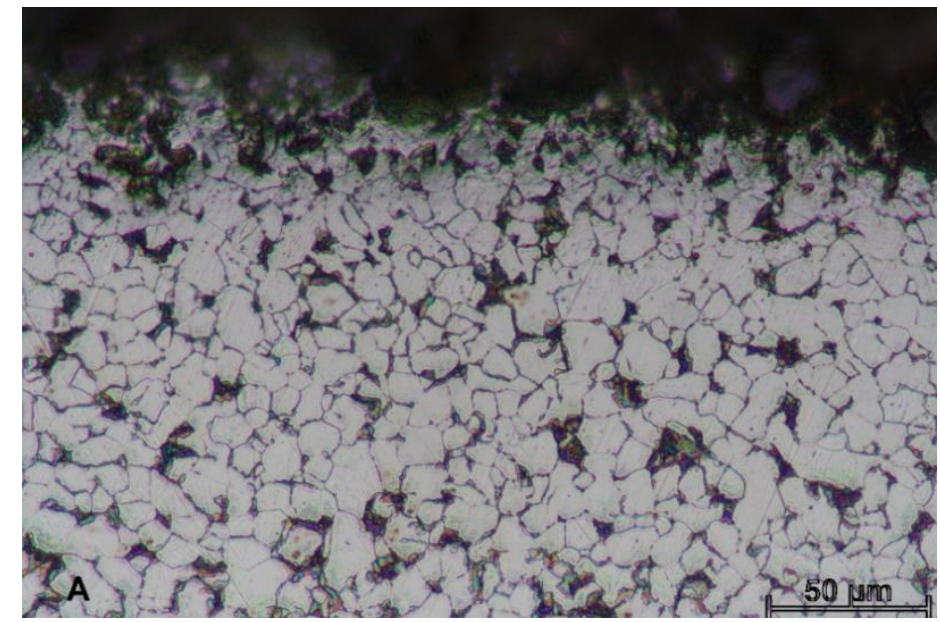




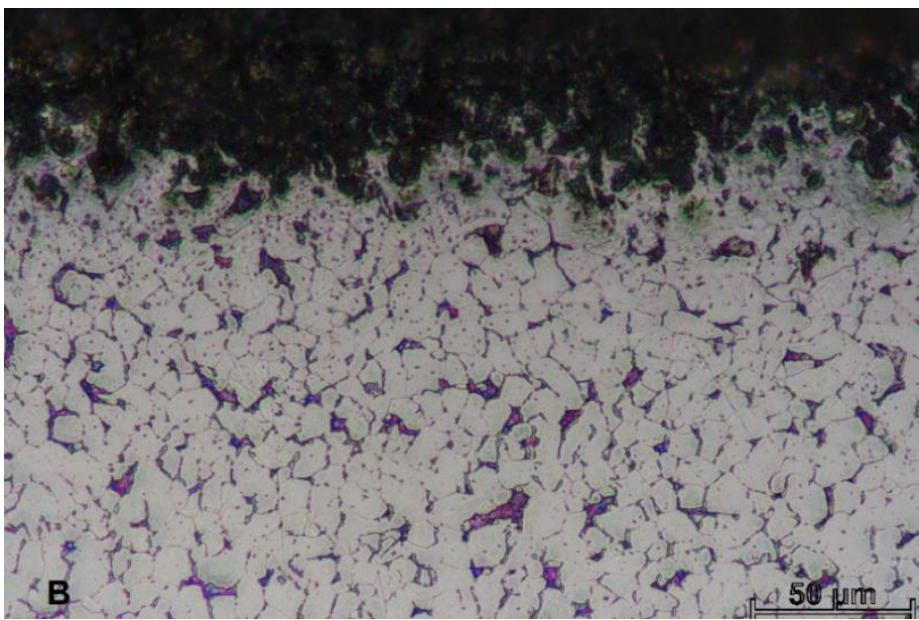

Figura 4: A microestrutura após os ensaios de desgaste nos sentidos longitudinal à laminação $(A)$ e transversal à laminação (B).

$\mathrm{Na}$ Figura 5 pode-se observar as topografias nas superfícies desgastadas, realizadas respectivamente longitudinalmente e transversalmente à direção de laminação.
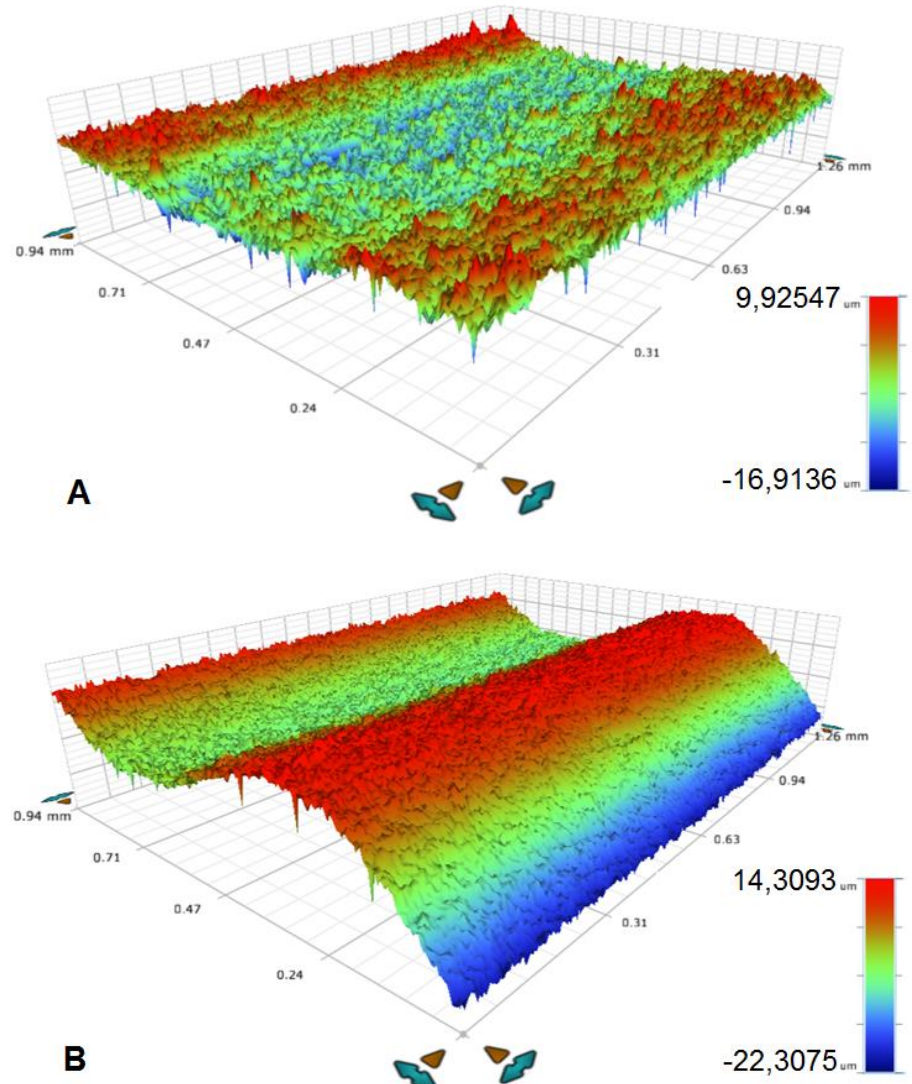
Figura 5: Imagens das superfícies desgastadas obtidas do perfilômetro no sentido longitudinal à laminação $(A)$, e no sentido transversal $(B)$.

A comparação das topografias mostra que a "ondulação" na condição transversal à laminação (fig.5B) é maior do que na condição longitudinal (fig. 5A), o que significa, em termos de desgaste abrasivo, que os sulcos deixados pela abrasão da areia são mais profundos. Entretanto, pode-se observar que a sua superfície é mais "lisa" se comparada à da condição longitudinal à laminação.

\section{DISCUSSÃO}

Pode-se observar que o desgaste no sentido transversal à laminação foi em média $9,6 \%$ menor que o desgaste no sentido longitudinal, e que o maior desgaste ocorreu no sentido à laminação com maior microdureza medida.

Comparando com os resultados da literatura, De Carvalho et al[8] realizaram ensaios do tipo roda de borracha empregando um aço manganês, com microestrutura texturizada (havia diferença das microestruturas nos sentidos longitudinal e transversal à laminação), e a taxa de desgaste no sentido transversal à laminação também foi menor do que aquela no sentido longitudinal. Uma explicação para esse comportamento é encontrada em um trabalho de Zum-Gahr[9], que mostra a relação entre a orientação de fibras estruturais com os desgastes sofridos por peças com as fibras no mesmo sentido da orientação e com sentido transversal a orientação delas. Segundo ele, fibras orientadas transversalmente à direção do desgaste acarretam em menor desgaste e fibras longitudinais à direção de desgaste têm mais facilidade em desgastar-se, o que demonstra coerência com os resultados encontrados no presente trabalho.

Além disso, Richardson[10] também cita que a deformação de um material está relacionada com a estrutura metálica dele. Segundo De Lima[11], estudos metalográficos verificaram que a resistência ao desgaste está diretamente relacionada com as características microestruturais do material. Ele cita também que a dureza da matriz tem menor influência no desgaste em comparação com a microestrutura, o que também indica coerência com os resultados obtidos nesse trabalho, quando relaciona-se a dureza com a resistência ao desgaste. No entanto, no presente trabalho não foi possível constatar diferenças microestruturais significativas entro os sentidos longitudinal e transversal à laminação. Desta forma, devem ser realizadas novas caracterizações no material com o objetivo de entender o porquê de o sentido transversal à laminação possuir maior resistência ao desgaste, mesmo apresentando valores de dureza menores.

\section{CONCLUSÃO}

Nos ensaios de abrasão à três corpos realizados, foi concluído que a direção de laminação em relação à direção do desgaste influencia no comportamento em desgaste do material. Os ensaios em que a direção da orientação do desgaste foi transversal à direção de laminação ocasionaram em uma taxa de desgaste 9,6\% menor do que os ensaios realizados com a direção da orientação longitudinal à direção de laminação.

\section{Agradecimentos}


Ao Conselho Nacional de Desenvolvimento Científico e Tecnológico (CNPq) e a Coordenação de Aperfeiçoamento de Pessoal de Nível Superior (CAPES) pelo apoio financeiro e concessão de bolsas, para as alunas Maria Vianna Rigatto e Daniela Fátima Giarollo, respectivamente. E à ArcelorMittal Tubarão por ceder o material para o estudo.

\section{REFERÊNCIAS}

1 Baptista ALB, Nascimento IA. Revestimentos duros resistentes ao desgaste depositados por soldagem utilizados na recuperação de elementos de máquinas. Spectru Instrumental Científico Ltda; 2014; [acesso em 21 ago. 2017]; $\quad$ p. $2-8 . \quad$ Disponível em: http://www.spectru.com.br/Metalurgia/diversos/soldadesgaste.pdf

2 Dettogni MA. Principais mecanismos de desgaste e avaliação de diferentes ligas para corpos moedores [dissertação de pós graduação]. Ouro Preto: Universidade Federal de Ouro Preto; 2010.

3 ASTM G40. Standard Terminology Relating to Wear and Erosion.

4 Eyre TS. Wear Characteristic of Metals. Source Book on Wear Control Tecnology. ASM; Metals Park; Ohio; 1976; 9(5); p. 203-212.

5 Kovaříková I, Szewczyková B, Blaškoviš P, Hodúlová E, Lechovič E. Study and Characteristic of Abrasive Wear Mechanisms. Eslováquia: Institute of Production Technologies, Faculty of Materials Science and Technology, Slovak University of Technology; 2009.

6 Villabón L, Sinatora A. Construção e Instrumentação de Abrasômetro do Tipo Roda-de-Borracha para o Estudo do Comportamento Tribológico de Aços. Revista da Associação Portuguesa de Análise Experimental de Tensões. 2006; 13; p. 1-10.

7 ASTM G65-16. Standard Test Method for Measuring Abrasion Using the Dry Sand/Rubber Wheel Apparatus.

8 De Carvalho AMB, Alcarria GC, Damião CA, Teles VC, da Silva Junior WM. Influencia da textura metalúrgica na abrasão de aços laminados a quente utilizados em mineração. In: POSMEC, Simpósio do Programa de PósGraduação em Engenharia Mecânica; 2016 Uberlândia. p. 1-5.

$9 \quad$ Zum-Gahr KH. Wear by Hard Particles, Tribology International. 1998.

10 Richardson RCD. Wear: The maximum hardness of strained surfaces and the abrasive wear of metals and alloys. 1967; 10(5); p. 353-382.

11 De Lima EC, Desenvolvimento e Análise das Pontas de Escavadeiras de Grande Porte com e sem Revestimento de Material Duro[dissertação de mestrado]. Belo Horizonte: Centro Federal de Educação Tecnológica de Minas Gerais ;2015. 